\title{
$\int_{0}^{\sqrt{6}}$ \\ Open Access: ISSN 1847-9286 \\ www.jESE-online.org
}

Short review

\section{Voltammetric and amperometric sensors for determination of epinephrine: A short review (2013-2017)}

\author{
Hadi Beitollahi ${ }^{1, \bigotimes}$, Mohadeseh Safaei ${ }^{1}$, Somayeh Tajik ${ }^{2}$ \\ ${ }^{1}$ Environment Department, Institute of Science and High Technology and Environmental Sciences, \\ Graduate University of Advanced Technology, Kerman, Iran \\ ${ }^{2}$ NanoBioElectrochemistry Research Center, Bam University of Medical Sciences, Bam, Iran
}

Corresponding authors E-mail: ${ }^{\bowtie}$ h.beitollahi@yahoo.com; Tel.: +98 3426226613; Fax: +98 3426226617

Received: July 16, 2018; Revised: September 13, 2018; Accepted: Septrember 19, 2018

\begin{abstract}
The present review focuses on voltammetric and amperometric methods applied for determination of epinephrine (EP) in last five years (2013-2017). Occurrence, role and biological importance of $E P$, as well as non-electrochemical methods for its assessment, are firstly reviewed. The electrochemical behavior of EP is then illustrated, followed by a description of the voltammetric and amperometric methods for EP content estimation in various media. Different methods for development of electrochemical sensors are reviewed, starting from unmodified electrodes to different composites incorporating carbon nanotubes, ionic liquids or various mediators. From this perspective, the interaction between functional groups of the sensor material and the analyte molecule is discussed, as it is essential for analytical characteristics obtained. The analytical performances of the voltammetric or amperometric chemical and biochemical sensors (linear range of analytical response, sensitivity, precision, stability, response time, etc.) are highlighted. Numerous applications of EP electrochemical sensors in fields like pharmaceutical or clinical analysis where EP represents a key analyte, are also presented.
\end{abstract}

\section{Keywords}

Epinephrine; electrooxidation; voltammetry: amperometry

\section{Contents}

1. Introduction

2. Epinephrine determination by non-electrochemical techniques - 28

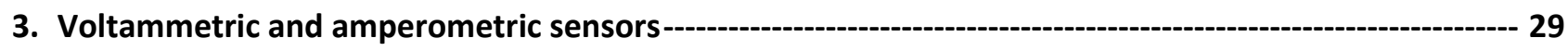

3. 1. Voltammetry/amperometry at bare/unmodified electrodes-o-29

3. 2. Voltammetry/amperometry at modified electrodes --o-ar

3. 2. 1. Chemically modified electrodes -- 
3. 2. 2. Modified electrodes with polymer $-31$

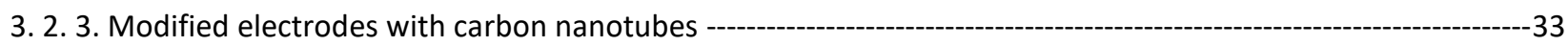

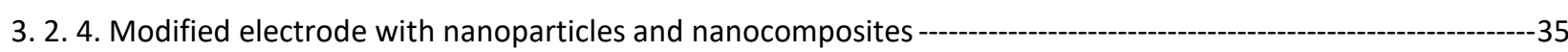

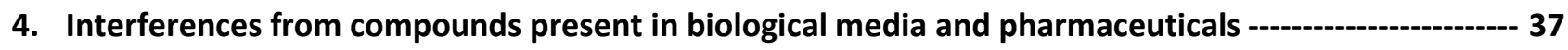

5. Analytical performances of electrochemical epinephrine sensors ---------------------------------------- 39

6. Some applications of electrochemical epinephrine sensors in pharmaceutical and biological fluid analysis

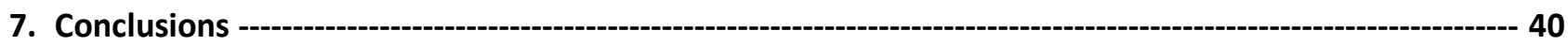

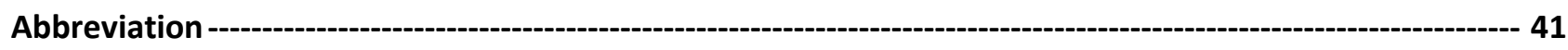

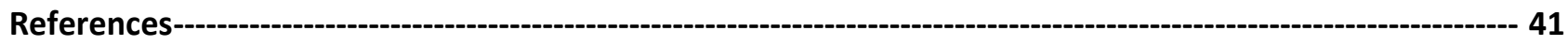

\section{Introduction}

Epinephrine (EP), also called adrenaline, is an important catecholamine neurotransmitter in the mammalian central nervous system [1]. Many life phenomena are related to the concentration of EP in blood. It also served as a chemical mediator for conveying the nerve pulse to efferent organs. Medically, EP has been used as a common emergency healthcare medicine [2,3]. EP is used to stimulate heartbeat and to treat emphysema, bronchitis, bronchial asthma and other allergic conditions, as well as the eye disease, glaucoma. Therefore, performing the research of EP has an important significance to medicine and life science [4]. EP is synthesized naturally in the body from L-tyrosine by the action of different enzymes. Almost $50 \%$ of the secreted hormone appears in urine as free and conjugated, $3 \%$ as vanilmandelic acid (VAM), the most abundant metabolite in urine [5]. Only small amounts of free EP are excreted. Meanwhile, EP is an electroactive compound and can be determined by electrochemical methods [6-11]. However, actual electrochemical detection of EP has two challenges. One is its low concentration level, while another challenge often encountered is the strong interference arising from electroactive compounds like norepinephrine (NE), dopamine (DA), ascorbic acid (AA) and uric acid (UA) [6]. To resolve these problems, one of the most common routes is using a modified electrode to improve the measuring sensitivity of EP and minimize the interference of $A A$ and UA to EP determination [7-12]. Although many modified electrodes have been demonstrated to be effective for detecting EP, there is still a need to develop a new method with high efficiency and convenience for the detection of EP $[13,14]$.

Injectable EP solutions used by emergency medical personnel and hospitals are principally degraded via oxidation. This degradation can be accelerated by heavy metals, ultraviolet light, exposure to oxygen, and increased $\mathrm{pH}$. Typical preventive measures for hindering oxidative degradation use light-resistant containers, buffered solutions, and/or antioxidants [15-20]. Due to the crucial role of EP in biochemistry and industrial applications, the determination of EP still presents research interest. Quick monitoring of EP levels during production and quality control stages is important [21-24]. In this review, we investigate the latest progress in modification of electrodes and its improvement in detection of EP.

\section{Epinephrine determination by non-electrochemical techniques}

Several methods have been reported for the determination of EP including high performance liquid chromatography (HPLC) [25,26], HPLC-mass spectrometry [27], fluorimetry [28], HPLC optical fiber biosensor [29], capillary electrophoresis [30,31], flow injection [32,33], HPLC with fluorimetric detection [34], chemiluminescence $[35,36]$ and spectrophotometry $[37,38]$. 


\section{Voltammetric and amperometric sensors}

Voltammetry is a potentiodynamic technique, based on measuring the current arising from oxidation or reduction reactions at the working electrode surface, when a controlled potential variation is imposed $[39,40]$. Amperometry is based on the application of a constant potential to a working electrode, and the subsequent measurement of the current generated by the oxidation/reduction of an electroactive analyte [41-43].

\section{1. Voltammetry/amperometry at bare/unmodified electrodes}

Bare electrodes without functionalization represent an interesting alternative, in particular when high sensitivity is not required. This approach has been realized by use of a simpler system, resulting in reduced costs for both production and use, and long-term stability. An electrochemical biosensor for the sensitive detection of EP was introduced by Li et al. [44]. Their results showed that the magnitude of the oxidation peak current of EP is related to many factors, including the $\mathrm{pH}$ value of the supporting electrolyte in the working electrode electrolytic cell, the acidity of the supporting electrolyte in the auxiliary electrode electrolytic cell, the distribution coefficients for different EP species, the properties of electrode surface charge and the molecular configuration of electroactive component. In performing experiments, $\mathrm{pH}$ of PBS buffer solution was kept at 7.0 in the working electrode electrolytic cell and $\mathrm{HCl}$ solution maintained at $1.0 \mathrm{~mol} \mathrm{~L}^{-1}$ in the auxiliary electrode electrolytic cell. The standard solutions of different amounts of EP were added to the working electrode electrolytic cell and the oxidation peak current of EP was recorded by cyclic voltammetry (CV). The range of $2.0 \times 10^{-7}-1.0 \times 10^{-4} \mathrm{~mol} \mathrm{~L}^{-1}$, with a detection limit of $6.2 \times 10^{-8} \mathrm{~mol} \mathrm{~L}^{-1}$ was obtained. Satisfactory results have been achieved for the determination of EP in injection. The recovery of the standard addition was in the range of $95.0-102.0 \%$.

Jemelkova et al. [45] reported the voltammetric behavior of EP investigated by differential pulse voltammetry (DPV) at a carbon paste electrodes (CPE) made with different carbon powders CR-2, glassy carbon (GC) microparticles, and single-wall carbon nanotubes (SWNT). In Briton-Robinson (BR) buffer solution ( $\mathrm{pH} \mathrm{6)}$, the linear dependence was found for the determination of EP by the given method in the concentration ranges of $1 \times 10^{-6}-1 \times 10^{-4}$ (CR-2), $1 \times 10^{-6}-1 \times 10^{-4}$ (GC microparticles) and $4 \times 10^{-6}-1 \times 10^{-4}$ (SWNT) mol L-1. Limits of detection were $8 \times 10^{-7}, 8 \times 10^{-7}$ and $2 \times 10^{-6} \mathrm{~mol} \mathrm{~L}^{-1}$, respectively. The best results were obtained by employing the CPE containing carbon paste with $50 \%(w / w)$ of SWNT, which showed a linear dynamic range of $4 \times 10^{-7}-1 \times 10^{-4} \mathrm{~mol} \mathrm{~L}^{-1}$ and a limit of detection $2 \times 10^{-7} \mathrm{~mol} \mathrm{~L}^{-1}$.

\section{2. Voltammetry/amperometry at modified electrodes}

The need for over-potential diminution and fouling minimization has required the electrode modification with a view to increase sensitivity and obtain more prominent peak separation. These properties are required mainly in complex media such as biological samples particularly prone to interferences, where EP coexists with other electroactive species.

\section{2. 1. Chemically modified electrodes}

Numerous electrochemical methods have been developed to determine EP on the basis of its electroactive nature. Most of these methods, however, have two major problems in EP determination which reduce accuracy and sensitivity of the results. The first is that in a natural environment, EP often coexists with a high concentration of electroactive biomolecules like UA, DA, $N E$, and $A A$ that interfere with each other. The second problem of reported methods is that the product of EP oxidation (epinephrine chrome) can easily transform into polymers, which block its 
further oxidation on the electrode surface. Hence, despite of considerable investigations, the preparation of a sensitive sensor with satisfactory selectivity and low detection limit with high sensitivity is still of great interest.

Development and application of L-glutamic acid functionalized graphene nanocomposite modified GCE for the determination of EP were reported by Kang et al. [46] Linear relationship between EP concentration and current response measured by DPV method was obtained in the range of $1 \times 10^{-7}$ to $1 \times 10^{-3} \mathrm{~mol} \mathrm{~L}^{-1}$ with a limit of detection of $3 \times 10^{-8} \mathrm{~mol} \mathrm{~L}^{-1}$. The modified electrode was employed to determine EP in urine with satisfactory results.

Zhang and Wang [47] have described $\beta$-Mercaptoethanol self-assembled monolayer modified electrode, fabricated on a bare gold (ME/Au SAMs). The films accelerated the electron transfer as mediators, and showed an excellent electrocatalytic activity for the oxidation of EP. The electrochemical behavior of EP at ME/Au SAMs has been studied by CV and the electrocatalytic mechanism is explored. At potential of $-0.044 \mathrm{~V}$ ( vs. SCE) in the aqueous buffer ( $\mathrm{pH} 4.0$ ), the first oxidation wave was observed for EP at the modified electrode (electrochemical oxidation of leucoepinephrine to epinechrome). In contrast, the first oxidation wave was not observed for NE or DA under same conditions.

Fabrication of modified GCE for determination of EP in aqueous solutions was reported by Ahmadian Yazdely et al. [48]. Their DPV results exhibited the linear dynamic range from $5.0 \times 10^{-8}$ to $1.1 \times 10^{-5} \mathrm{~mol} \mathrm{~L}^{-1}$ and detection limit of $2.3 \times 10^{-8} \mathrm{~mol} \mathrm{~L}^{-1}$ for EP. In addition, the analytical performance of the modified electrode for quantification of EP in real samples was evaluated.

Sharath Shankar and Kumara Swamy [49] have successfully investigated tetradecyltrimethyl ammonium bromide (TTAB) surfactant immobilized at CPE which has been proposed for simultaneous investigation and determination of EP and serotonin (5-HT) in presence of AA. Voltammetric techniques in the phosphate buffer solution (PBS) ( $\mathrm{pH} 7.4$ ) were applied. The anodic peak of EP was observed at $198 \mathrm{mV}(v s . \mathrm{Ag} / \mathrm{AgCl} / \mathrm{KCl})$ at the scan rate $50 \mathrm{mV} \mathrm{s}^{-1}$. The interference studies showed that the modified electrode exhibits excellent selectivity for the determination of EP in the presence of large excess of AA and 5-HT. Differences of the oxidation peak potentials for EP-AA and EP-5-HT were about 215 and $165 \mathrm{mV}$, respectively. Detection limit of the modified electrode obtained by DPV technique was found to be $0.12 \mu \mathrm{mol} \mathrm{L}^{-1}$. The developed method was applied to the determination of EP in synthetic samples with satisfactory results.

Jahanbakhshi [50] reported a synthesis of mesoporous carbon foam (MCF) with particular properties due to simplistic and template-free procedure. The synthesized MCF was characterized by transmission electron microscopy, field emission scanning electron microscopy, $\mathrm{X}$-ray diffraction and BET surface area techniques. Porous MCF, with pore diameters of 5 to $10 \mathrm{~nm}$ resulted in extensive specific surface area that modifies the electrode surface. The obtained MCF was dispersed in the Salep solution to prepare a stable suspension (S-MCF). The resultant composite was casted on the surface of GCE to assemble the S-MCF modified GCE electrode (S-MCF/GCE). CV method was used to study electrochemical behavior and determination of EP was conducted by applying DPV method in the presence of UA. In the optimized conditions, the presented sensor was found able to detect the concentration range of $0.1-12 \mu \mathrm{mol} \mathrm{L}-1$ with a limit of detection of $40 \mathrm{nmol} \mathrm{L^{-1 }}$. The presented methodology possesses a reliable reproducibility, repeatability and stability in biological samples.

Sensitive and selective determination method for EP was developed by Chandrashekar et al. [51] by immobilization of TX-100 surfactant on the bare CPE. The catalytic activity of the modified electrode for the oxidation of EP was determined using CVs recorded at different scan rates. The 
effect of the solution $\mathrm{pH}$ on the voltammetric response of EP was examined using the phosphate buffer solution. The TX-100/CPE demonstrated a good performance for the determination of EP in the concentration range from 10 to $50 \mu \mathrm{mol} \mathrm{L} \mathrm{L}^{-1}$, with a detection limit of $1 \times 10^{-6} \mathrm{~mol} \mathrm{~L}^{-1}$. The application was conducted for the determination of EP in a human serum sample and the sensor was proven to be rapid, having excellent selectivity and repeatability.

In the research of Dehghan Tezerjani et al. [52], an electrochemical sensor was constructed for determination of EP. The sensor was based on the CPE modified with graphene oxide (GO) and 2-(5-ethyl-2,4- dihydroxyphenyl)-5,7-dimethyl-4 H-pyrido (2,3-d) (1,3) thiazine-4-one (EDDPT) as modifiers. The modified electrode was applied as an electrochemical sensor for oxidation of EP. Under the optimum conditions, the overpotential value for EP oxidation decreased for about $279 \mathrm{mV}$ at the modified CPE more than at non-modified CPE. Also, the designed electrochemical sensor was applied to determine EP in the drug sample and for simultaneous determination of EP, ACT and DA in human serum solutions.

\section{2. 2. Modified electrodes with polymer}

In recent years, electrochemically modified electrodes with conductive or redox polymers have been widely used owing to their excellent and unique physical and chemical properties. This kind of modification is established as the best approach for selective determination of some biomolecules because the surface characteristic on the electrode can be modulated by introducing various chemicals with reactive groups. The polymer-modified electrodes showed broad potential windows and can still catalyze electrochemical reactions which have high overpotential and poor selectivity.

Electropolymerization of fuchsine acid (FA) was studied by Taei et al. [53] on the surface of GCE in different electrolyte media. Then, a novel Au-nanoparticle poly(FA) film modified GCE (poly(FA)/AuNP/GCE) was constructed for the simultaneous determination of AA, EP and UA. In addition, for the poly(FA)/AuNP/GCE, oxidation peak potentials of AA-EP and EP-UA were found separated for $150 \mathrm{mV}$ and $180 \mathrm{mV}$, respectively. At the same time, for the bare GCE, not any separation was noticed. DPV results exhibited the linear dynamic range of 0.5-792.7 $\mu \mathrm{mol} \mathrm{L}^{-1}$ for EP with the detection limit of $0.01 \mu \mathrm{mol} \mathrm{L^{-1 }}$. The diffusion coefficient for the oxidation reaction of EP on AuNP/poly (FA) film coated GC electrode was calculated as $2.6( \pm 0.10) \times 10^{-5} \mathrm{~cm}^{2} \mathrm{~s}^{-1}$.

$\mathrm{Li}$ and Wang [54] have investigated an electrochemical sensor based on the poly(guanine) (PGA) modified GCE that was fabricated by electropolymerization of guanine on the bare GCE surface. This modified electrode exhibited good electrocatalytic property towards the oxidation of EP and UA in $0.1 \mathrm{~mol} \mathrm{~L}^{-1} \mathrm{PBS}$ ( $\mathrm{pH} 4.0$ ), seen as enhanced peak currents and well defined peak separations. Under optimum reaction conditions, oxidation peak currents of EP and UA were proportional to their concentrations in the range of $1.0 \times 10^{-5}$ to $1.0 \times 10^{-3} \mathrm{~mol} \mathrm{~L}^{-1}$ and detection limit of $1.8 \times 10^{-6} \mathrm{~mol} \mathrm{~L}^{-1}$ was determined for both compounds. Finally, this method was efficiently used for the determination of EP in EP injections.

Kocak and Dursun [55] used a modified electrode that was fabricated by overoxidation of polymer film after electropolymerization of $p$-aminophenol on a bare GCE. Higher catalytic activity was observed for electrocatalytic oxidation of AA, EP, and UA in PBS (pH 7.4) at the overoxidized poly(p-aminophenol) film modified GCE (Ox-PAP/GCE), due to enhanced peak current and well defined peak separations compared to both bare GCE and poly ( $p$-aminophenol) film modified GCE (PAP/GCE).

Devadas et al. [56] presented for the first time, a simultaneous voltammetric determination of EP and p-acetoaminophenol (AP) on the poly(curcumin) (1,7 bis((4-hydroxy-3-methoxyphenyl)-1,6- 
-heptadiene-3,5 dione) modified GCE. Curcumin (CM) was polymerized onto the GCE surface by simple electropolymerization process. Low peak to peak $\left(\Delta E_{\mathrm{p}}\right)$ separation of $60 \mathrm{mV}$ was observed, indicating fast electron transfer between poly $(\mathrm{CM})$ and the electrode surface. Moreover, the poly(CM) modified GCE exhibited enhanced electrocatalytic activity for EP in the linear range of 4.97-230.76 $\mu \mathrm{mol} \mathrm{L}^{-1}$ and very low detection limit (LOD) of $0.05 \mu \mathrm{mol} \mathrm{L}-1$.

Taei and Jamshidi [57] introduced a polymerized film of Adizol Black B (ABB) on the surface of GCE for the simultaneous determination of AA, EP and UA. This new modified electrode presented an excellent electrocatalytic activity towards the oxidation of AA, EP and UA by DPV method. The separation of the oxidation peak potentials for AA-EP and EP-UA were at about 180 and $130 \mathrm{mV}$, respectively. The diffusion coefficient for the oxidation reaction of EP at the poly(ABB) film coated GCE was calculated as $1.54( \pm 0.10) \times 10^{-4} \mathrm{~cm}^{2} \mathrm{~s}^{-1}$.

Ma et al. [58] demonstrated an electrochemical sensor based on the silver doped poly-L-cysteine film (Ag-PLC) that has been fabricated for simultaneous determination of DA, EP and UA in the presence of AA. Although voltammetric signals of DA and EP were resolved the bare GC electrode, the signals of DA and UA were not resolved in a mixture. However, (Ag-PLC) modified electrode does not only separate voltammetric signals of DA, EP and UA with potential difference of 390 and $135 \mathrm{mV}$ between DA-EP in the cathodic peak potential and UA-(DA+EP) in the anodic peak potential respectively, but also shows higher electrocatalytic activity towards DA, UA and EP in the presence of high concentration of AA. For EP, the linear range was determined from $5.00 \times 10^{-6}$ to $1.10 \times 10^{-4} \mathrm{~mol} \mathrm{~L}^{-1}$. The practical application for this modified electrode was demonstrated by determining the concentration of DA, UA and EP in human urine samples.

$\mathrm{Li}$ and Sun [59] introduced a novel paladium doped poly(L-arginine) modified electrode (Pd-PLA/GCE), fabricated by electrochemical immobilization of the paladium doped poly (L-arginine) on a GCE. This modified electrode was used for determination of EP by the CV method. The method was successfully applied to the determination of EP in injection with satisfactory results.

A simple and sensitive poly(L-aspartic acid)/electrochemically reduced graphene oxide modified GCE, poly(L-Asp)/ERGO/GCE, has been constructed by electrochemical reduction of GO that was drop coated on the GCE within $2 \mathrm{mmol} \mathrm{L}^{-1} \mathrm{~L}$-aspartic acid in PBS (pH 6). As suggested by Mekassa et al [60], this procedure gives rise to in situ polymerization of L-aspartic acid on the ERGO. Significant enhancement of the peak current response of EP was observed, accompanied with a negative shift in the peak potential value at the composite modified electrode, compared to the bare electrode. Real sample analysis was carried out in the pharmaceutical formulation of EP hydrochloride injection, which revealed good recovery results of 94-109\%.

According to Vieira da Silva [61], the polymerization of ferulic acid (FA), forming poly(FA) on MWCNTs modified GCE was performed and the modified platform applied for simultaneous determination of $N A D H, E P$ and $D A$. CV and CA methods were employed to investigate the electrocatalytic oxidation of NADH, EP and DA on the modified electrode in aqueous solutions. The

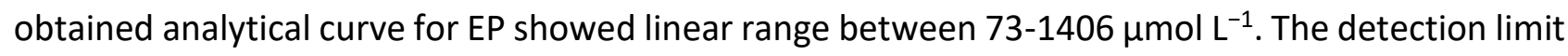

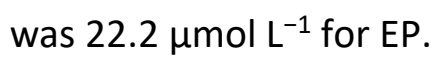

Poly(ionic liquids), (PILs), have been applied as the linkers between Au nanoparticles and polypyrrole nanotubes (PPyNTs) for the synthesis of Au/PILs/PPyNTs hybrids. As was reported by Mao et al. [62], due to the presence of PILs, high density of well dispersed AuNPs was deposited on the surface of PILs/PPyNTs by anion exchange with Au precursor and in situ reduction of metal ions. The catalytic oxidation peak current obtained by DPV method increased linearly with increasing EP concentration in the range of $35-960 \mu \mathrm{mol} \mathrm{L}^{-1}$ with a detection limit of $298.9 \mathrm{nmol} \mathrm{L}$, according to 
the criterion of a signal-to-noise ratio $(\mathrm{S} / \mathrm{N}=3)$. These results suggested that this modified electrode shows excellent electrocatalytic activity towards this significant hormone in human life.

\section{2. 3. Modified electrodes with carbon nanotubes}

Carbon nanotubes (CNTs) have attracted more attention in physical, chemical and material science fields due to their unique electrical conductivity, chemical stability and high mechanical strength and modulus. The subtle electronic properties of carbon nanotubes suggest that they are able to promote electron transfer when used as the electrode material in electrochemical reactions. These properties provided a new manner of electrode surface modification for designing new electrochemical sensors and novel electrocatalytic materials.

In the research performed by Apetrei [63], a biosensor comprising tyrosinase immobilized on a SWCNTs modified GCE was developed for determination of EP. Tyrosinase maintained high bioactivity on this nanomaterial by catalyzing the oxidation of EP to EP quinone, which was electrochemically reduced $(-0.07 \mathrm{~V}$ vs. $\mathrm{Ag} / \mathrm{AgCl})$ on the biosensor surface. Under optimum conditions, the biosensor showed a linear response in the range of $10-110 \mu \mathrm{mol} \mathrm{L}^{-1}$ and a limit of detection was calculated as $2.54 \mu \mathrm{mol} \mathrm{L}^{-1}$ with a correlation coefficient of 0.977 for EP. The repeatability, expressed as the relative standard deviation for five consecutive determinations of $10^{-5} \mathrm{~mol} \mathrm{~L}^{-1}$ EP solution, was $3.4 \%$.

Valentini et al. [64] used oxidized single wall carbon nanohorns (o-SWCNHs) for the first time, in order to assemble chemically modified screen printed electrode (SPE) that is selective towards the electrochemical detection of EP in the presence of serotonine-5-HT (S-5HT), DA, NE, AA, ACT and UA. EP neurotransmitter was detected by using DPV in a wide linear range of concentrations (2-2500 $\mu \mathrm{mol} \mathrm{L}^{-1}$ ) with high sensitivity, very good reproducibility (RSD ranging from 2 to $10 \%$ for different SPEs), short response time for each measurement (only 2 s) and low detection limit (LOD = $0.1 \mu \mathrm{mol} \mathrm{L} \mathrm{L}^{-1}$ ).

A simple electrochemical sensor for EP has been developed by Ghica and Brett [65]. They modified a carbon film electrode (CFE) with MWCNTs in a chitosan matrix. Under optimum conditions ( $\mathrm{pH} 7.0$ ), the MWCNT/CFE electrode showed significant electrocatalytic oxidation of EP with a decrease of overpotential value for about $200 \mathrm{mV}$ and 11-fold increase of the peak current value, compared to the unmodified CFE. The sensor exhibited excellent stability over a period of 6 months and was successfully applied to the analysis of injectable adrenaline solutions.

The electrochemical behavior of a multi walled carbon nanotube paste electrode modified with 2-((7-(2,5-dihydrobenzylideneamino) heptylimino methyl) benzene-1,4-diol (DBHB) was studied by Mazloum Ardakani et al. [66]. CV method was used to study the electrocatalytic mechanism of EP electrooxidation at the modified electrode. Catalytic rate constant and diffusion coefficient were obtained for oxidation of EP. By using DPV method, a highly selective and simultaneous determination of EP, acetaminophen and folic acid has been obtained at the modified electrode used as an electrochemical sensor.

Wu et al. [67] reported a sensor for EP that is based on ITO electrode modified with MWCNTs being pre-coated with a polymerized ionic liquid (PILMWNTs). The chitosan film was electrodeposited on the ITO electrode in the presence of EP and the PILMWNTs. This film acts as an excellent recognition matrix due to excellent film forming ability and many functional groups that favor hydrogen bond formation with the target EP. The electrochemical response to EP was linear in $0.2 \mu \mathrm{mol} \mathrm{L} \mathrm{L}^{-1}$ to $0.67 \mathrm{mmol} \mathrm{L}^{-1}$ concentration range, and detection limit was as low as $60 \mathrm{nmol} \mathrm{L}^{-1}$ (at $\mathrm{S} / \mathrm{N}=3$ ). 
Wang et al. [68] demonstrated a modified GCE that was covered with a layer of MWCNT coated with hexadecyltrimethyl ammonium bromide (CTAB). The modified electrode showed excellent electrochemical catalytic properties for the redox reaction of EP and $A A$. In the presence of CTAB, the peak separation between EP and AA can be broadened to $256 \mathrm{mV}$ by the CTAB.

Graphite paste electrode (GPE) modified with 1-butyl-3-methylimidazolium hexafluoro phosphate $\left(\mathrm{BMIMPF}_{6}\right)$ and $\mathrm{MWCNTs}$ was prepared for simultaneous voltammetric determination of EP and xanthine (XN) by Rajabi et al. [69]. The prepared electrode (BMIMPF 6 -MWCNT/GPE) showed excellent catalytic activity in the electrochemical oxidation of EP and $\mathrm{XN}$, leading to remarkable enhancement of the corresponding peak currents and lowering the peak potentials. The peak current values of linear sweep voltammograms increased linearly with EP concentrations in the range of $0.30-60 \mu \mathrm{mol} \mathrm{L}^{-1}$ in $0.1 \mathrm{~mol} \mathrm{~L}^{-1} \mathrm{PBS}(\mathrm{pH} 7.0)$. Applicability of this modified electrode as the voltammetric biosensor was demonstrated by simultaneous determination of EP and XN in human urine, human blood serum and ampoule.

In the study of Babaei et al. [70], electrooxidation of EP, ACT and mefenamic acid (MEF) has been investigated by application of nickel hydroxide nanoparticles/MWCNT modified GCE (MWCNT-NHNPs/GCE) using CV and DPV methods.

In another study, Pradhan et al. [71] employed a composite electrode for the amperometric detection of EP. Composite electrode was developed by electropolymerizing bromothymol blue (BTB) on the CPE bulk modified with MWCNTs. Electropolymerization of BTB on the surface of CPE involved much less energy compared to a CPE surface. The modification enhanced the current sensitivity of EP by 5.5 times as compared to the bare CPE. The sensor showed the optimum current response at physiological $\mathrm{pH}$ and the response was linear for the concentration of EP in the ranges

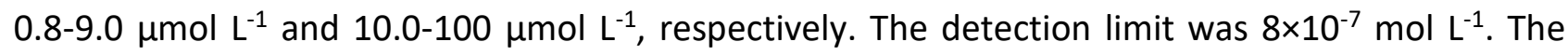
amperometric response of EP remained unaltered even in the presence of 50-fold excess of UA, AA and 100-fold excess of L-Tryptophan, L-Tyrosine, L-cysteine and nicotinamide adenine dinucleotide. This sensor showed stability, reproducibility, antifouling effects and was successfully applied for the determination of EP in blood serum and adrenaline injection.

Thomas et al. [72] developed an amperometric sensor for the determination of EP which was fabricated by modifying the CPE with pristine multi walled carbon nanotubes (pMWCNTs). Bulk modification, followed by a drop casting of sodium dodecyl sulfate (SDS) onto the surface for its optimal potential application was performed. Analytical applications of the modified electrode were demonstrated by determining EP in spiked blood serum and adrenaline tartrate injection.

Filho et al. [73] developed an electrochemical method for the single and simultaneous determination of DA and EP in human body fluids, using a GCE modified with nickel oxide nanoparticles and carbon nanotubes within a dihexadecyl phosphate film. SWV and DPV methods were applied. By using DPV with the proposed electrode, a separation of ca. $360 \mathrm{mV}$ between the peak reduction potentials of DA and EP was present in binary mixtures. The detection limit of EP was determined as $8.2 \times 10^{-8} \mathrm{~mol} \mathrm{~L}^{-1}$.

Koteshwara Reddy et al. [74] checked out an efficient electrochemical sensor for selective detection of EP. It was fabricated with the aid of a functionalized MWCNT-chitosan biopolymer nanocomposite (Chit-f CNT) electrode. MWCNTs were successfully functionalized with the aid of nitric acid and confirmed by the Raman spectral data. Functionalized carbon nanotubes ( $\mathrm{fCNT}$ ) were dispersed in chitosan solution and the resulting bio nanocomposite was used for the fabrication of sensor surface by drop and cast method. Electrochemical characteristics of the fabricated sensor were understood using CV and DPV analysis for the detection of EP in PBS ( $\mathrm{pH}$ 7.4). 


\section{2. 4. Modified electrode with nanoparticles and nanocomposites}

Nanotechnology and nanoscience represent new and enabling platforms that promise to provide a broad range of novel uses and improved technologies for environmental, biological and other scientific applications. One of the reasons staying behind the intense interest is that nanotechnology permits the controlled synthesis of materials, where at least one dimension of a structure is less than $100 \mathrm{~nm}$. Nanostructured materials have also been incorporated into electrochemical sensors for biological and pharmaceutical analyses. While they offer unique advantages, including enhanced electron transfer, large edge plane/basal plane ratios and rapid kinetics of the electrode processes.

In a study of Sadeghi et al. [75], CPE was modified with zinc oxide ( $\mathrm{ZnO}$ ) nanoparticles and 1,3-dipropylimidazolium bromide was used as a binder. It was found that the oxidation of EP at the surface of modified electrode occurs at about $80 \mathrm{mV}$ less positive potential than at unmodified CPE. DPV peak current values showed a linear relationship with concentration of EP in the range of 0.09-

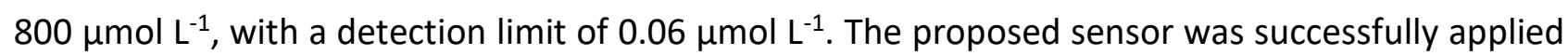
for the determination of EP in real samples.

As suggested by Babaei et al. [76], simultaneous determination of EP and ACT can be performed using a GCE modified with a MWCNTs, nickel hydroxide nanoparticles (NHNPs) and Mg-Al layered double hydroxide (LDH) composite (MWCNTs-NHNPs-LDH/GCE). Based on DPV method, the

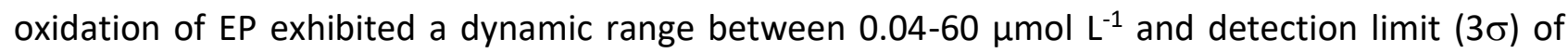
$11 \mathrm{nmol} \mathrm{L}^{-1}$. This method was used for the determination of EP in real samples, using the standard addition method.

Gold nanoparticles/polyaniline nanocomposite thin film was deposited on to the surface of GCE by Langmuir-Blodgett (LB) technology to fabricate a new voltammetric sensor (GNPs/PAn-LBGCE) for EP and UA detection, as was reported by Zou et al. [77]. Electrochemical behavior of EP and UA at the modified electrode was investigated in PBS ( $\mathrm{pH}$ 6.6).

Silai et al. [78] have reported a modified electrode that was prepared by immobilizing Ptnanoparticles into a chitosan film. The investigation of the influence of experimental conditions (scan rate, frequency, $\mathrm{pH}$ ) on the electrochemical behavior of EP was realized by the CV method.

Novel $\mathrm{MCM} / \mathrm{ZrO}_{2}$ nanoparticles modified CPE was fabricated and used by Mazloum-Ardakani et al. [79], in order to study the electrooxidation of EP and ACT and their mixtures. The modified electrode showed electrocatalytic activity toward EP and ACT oxidation with a decrease of the overpotential value by $173 \mathrm{mV}$ for EP at the surface of the MZ-CPE and an increase in peak current at $\mathrm{pH} 7.0$.

Jin and Zhang [80] used the nanogold modified GCE obtained by electrodeposition, which can catalytically oxidize and accumulate EP. In this research, effects of changes of $\mathrm{pH}$ and concentration of PBS on the electrochemical behavior of EP were studied. This modified electrode could be applied for determination of EP in the presence of AA. DPV data showed that under optimal conditions, the obtained anodic peak currents were linearly dependent on the EP concentration in the range of $1.0 \times 10^{-4}-1.0 \times 10^{-6} \mathrm{~mol} \mathrm{~L}^{-1}$.

Razavian et al. [81] employed electrochemical sensor that was developed and tested for detection of L-tyrosine in the presence of EP. The electrode was prepared by surface modification of a GCE with nafion and cerium dioxide nanoparticles. The modified electrode exhibited a significant electrochemical oxidation effect of EP in a $0.2 \mathrm{~mol} \mathrm{~L}^{-1}$ Britton-Robinson (BR) buffer solution $(\mathrm{pH} 2)$. The electro-oxidation peak current increased linearly with the EP concentration in the molar concentration range of 5 to $220 \mu \mathrm{mol} \mathrm{L}^{-1}$. By employing DPV method for simultaneous 
measurements, two reproducible peaks for L-tyrosine and EP in the same solution with a peak separation of about $443 \mathrm{mV}$ were detected.

Nitrogen doped three dimensional porous graphene (NG) modified electrode was fabricated by Yang et al. [82]. The obtained data showed that electrooxidation of EP at the modified electrode is greatly facilitated, which was ascribed to the excellent properties of NG. The modified electrode was used for simultaneous determination of EP and metanephrine (MEP). DPV peak currents of EP increased linearly with their concentration within the range of $1.0 \mu \mathrm{mol} \mathrm{L}^{-1}$ to $1.0 \mathrm{mmol} \mathrm{L}^{-1}$, with a sensitivity of $0.021 \mu \mathrm{A} /\left(\mu \mathrm{mol} \mathrm{L}^{-1}\right)$ for EP. The detection limit for EP was ascertained to be $0.67 \mu \mathrm{mol} L^{1}$. Additionally, the detection of EP and MEP was found possible in the presence of AA and UA. The modified electrode was applied to the detection of EP and MEP in human plasma samples with recoveries from $98.9 \%$ to $100.9 \%$, and EP hydrochloride injections with recoveries from $100.3 \%$ to $104.6 \%$.

Chen and Ma [83] used a graphene modified GCE obtained via drop casting method and applied it to the simultaneous detection of EP, UA, and AA by CV method in a PBS solution (pH 3.0). The oxidation potentials of EP, UA, and AA at the graphene modified GCE were $0.484,0.650$, and $0.184 \mathrm{~V}$ (vs. $\mathrm{Ag} / \mathrm{AgCl}$ ), respectively. Peak separations between EP and UA, EP and $A A$, and UA and AA were about 166, 300, and $466 \mathrm{mV}$, respectively.

A hybrid membrane, consisting of aminated graphene and Ag nanoparticles, (AgNPs), was prepared on the surface of GCE by the CV method, where aminated graphene $\left(\mathrm{GR}-\mathrm{NH}_{2}\right)$ acted as a matrix for immobilizing AgNPs. The morphology and electrochemical properties of this hybrid membrane were characterized together with the voltammetric behavior of EP in a study of Huanhuanin et al. [84]. The membrane exhibited excellent eletrocatalytic activity for the redox reaction of EP and resolved the electrochemical response of EP and UA into two oxidation peaks.

According to Mak et al. [85], organic electrochemical transistors (OECTs) were found to be excellent transducers for various types of biosensors. It was highly sensitive EP sensor based on OECTs prepared on glass substrates by solution process. The device performance was optimized by immobilizing Nafion and carbon based nanomaterials on the gate electrodes of the OECTs. The detection limit of the sensors was as low as $0.1 \mathrm{nmol} \mathrm{L}^{-1}$, which could cover the concentration level of EP in medical detections.

In a study performed by Beitollahi et al. [86], CPE modified with vinyl ferrocene (VF) and CNTs was used for the sensitive and selective voltammetric determination of EP, which could be related to the strong electrocatalytic effect of the VF and CNT towards this compound. The mediated oxidation of EP at the modified electrode was investigated by CV. SWV method of EP at the modified electrode exhibited linear dynamic ranges with a detection limit of $3.0 \times 10^{-8} \mathrm{~mol} \mathrm{~L}^{-1}$. SWV was also used for simultaneous determination of EP and tryptophan at the modified electrode. Quantification of EP and tryptophan in some real samples was performed by the standard addition method.

Zhang et al. [87] described a facile preparation of polydopamine (PDA)-nanogold composite modified GCE used for the sensitive determination of EP, DA, AA and UA simultaneously. Under mild spontaneous reaction condition, DA as a reducing agent and monomer and $\mathrm{HAuCl}_{4}$ as an oxidant trigger for DA polymerization were mixed together with the source of gold nanoparticles to yield a composite of DA polymer and gold nanoparticles. These composite particles were then anchored on GCE by electropolymerization of the remaining DA monomer. The resultant electrode exhibited excellent electrocatalytic redox activities toward EP, DA, AA and UA. Furthermore, although the oxidation peaks of EP and DA at the modified electrode appeared at the same potential of $230 \mathrm{mV}$ 
(vs. $\mathrm{Ag} / \mathrm{AgCl}$ ), three well defined oxidation peaks were generally obtained for AA, EP, DA and UA (50, 230, $380 \mathrm{mV}$ vs. Ag/AgCl).

In a study of Redin el al. [88], a green approach for the preparation of carbon black (CB) and electrochemically reduced graphene oxide composite (ERGO) was described. Electrochemical sensors were based on screen printed carbon electrodes (SPCES), fabricated on poly (ethylene terephthalate) (PET). The SPCE/CB-ERGO sensor was tested with DA, EP and paracetamol (PCM), exhibiting an enhanced electrocatalytic performance compared to the bare SPCE.

In another study, Gupta et al. [89] have synthesized NiO/CNTs nanocomposite and applied it for fabrication of NiO/CNTs nanocomposite modified CPE (CPE/NiO/CNTs) as SWV sensor for the determination of EP. The electrooxidation signal of EP showed an irreversible response at $0.3 \mathrm{~V}$ (vs. $\mathrm{Ag} / \mathrm{AgCl}$ ). The oxidation current of EP was doubled compared to a CPE. At the best electrochemical conditions, the voltammetric oxidation signal of EP showed linear dynamic range (0.08-900.0 $\left.\mu \mathrm{mol} \mathrm{L}^{-1}\right)$, with detection limit of $0.01 \mu \mathrm{mol} \mathrm{L}^{-1}$.

Electrochemical sensor developed by Anithaa et al. [90] for the simultaneous determination of EP and xanthine is based on the gamma irradiated SDS-WO3 NPs. The fabricated sensor exhibited wide linear range $\left(0.009-1000 \mu \mathrm{mol} \mathrm{L}^{-1}\right)$ with low detection limit $\left(1.8 \mathrm{nmol} \mathrm{L}{ }^{-1}\right)$ for EP.

Tsele et al. [91] studied electrochemical properties of functionalized MWCNT/polyaniline (PANI) doped with metal oxide $\left(\mathrm{TiO}_{2}, \mathrm{RuO}_{2}\right)$ nanoparticles. Successful syntheses of $\mathrm{MWCNT}, \mathrm{TiO}_{2}, \mathrm{RuO}_{2}$, PANI, MWCNT-PANI-TiO ${ }_{2}$ and $\mathrm{MWCNT}-\mathrm{PANI}-\mathrm{RuO}_{2}$ nanomaterials were confirmed using suitable characterization techniques. Au-MWCNT-PANI-TiO 2 and Au-MWCNT-PANI-RuO 2 modified electrodes showed the best electron transport properties towards the oxidation of EP, compared with other electrodes investigated. The Tafel values obtained in the presence of EP as 0.448 and $0.442 \mathrm{~V} /$ decade for Au-MWCNT-PANI-TiO 2 and Au-MWCNT-PANI-RuO 2 electrodes respectively, suggested adsorption due to analyte oxidation intermediates products. The linear calibration plot for EP was obtained in the concentration range of 4.9 to $76.9 \mu \mathrm{mol} \mathrm{L}^{-1}$, while a limit of detection for Au-MWCNT-PANI-TiO ${ }_{2}$ electrode was $0.16 \mu \mathrm{mol} \mathrm{L}^{-1}$.

\section{Interferences from compounds present in biological media and pharmaceuticals}

Interference studies were carried out with several chemical substances prior to the application of the proposed method for the assay of EP in urine samples and the injection solution. The potential interfering substances were chosen from the group of substances commonly found with EP in pharmaceuticals and biological fluids. In biological environments, AA is commonly present with EP and may be oxidized at similar potential as EP.

In the research performed by Kang et al. [46], CVs of EP and AA were respectively recorded at the L-glutamic acid-graphene/GCE. The results showed that the oxidation peak of EP is not affected by presence of AA. This means that the modified electrode is able to distinguish EP from AA.

The influence of various foreign species on the determination of $50.0 \mu \mathrm{mol} \mathrm{L}^{-1} \mathrm{EP}, 100.0 \mu \mathrm{mol} \mathrm{L} \mathrm{L}^{-1}$ AA and $50.0 \mu \mathrm{mol} \mathrm{L}^{-1}$ UA was investigated by Taei et al. [53]. The tolerance limit was taken as the maximum concentration of the foreign substance(s) which caused an approximately $\pm 5 \%$ relative error in the determination. It was also found that $\mathrm{Mg}^{+2}, \mathrm{Ca}^{+2}, \mathrm{SO}_{4}^{-2}, \mathrm{Br}^{-}, \mathrm{K}^{+}, \mathrm{NO}^{-}, \mathrm{ClO}_{4}^{-}$glycine, glucose, sucrose, lactose, fructose, valine, aspartic acid, urea, and saturation of starch solution did not interfere with the determination of these compounds. However, greater amounts of cysteine (40-fold), oxalate ion ( 100 -fold), and citric acid ( 30 -fold) did cause interference in the simultaneous determination of EP, AA and UA by poly(fuchsine acid) modified GCE. 
As was reported by Ahmadian Yazdely et al. [48], the maximal tolerable concentration of foreign substances was, by using the thiourea modified GCE, determined as $5.0 \times 10^{-5} \mathrm{~mol} \mathrm{~L}^{-1}$ for glucose, uric acid, ascorbic acid, citric acid, dopamine, and $\mathrm{Na}^{+}, \mathrm{K}^{+}, \mathrm{Cu}^{2+}, \mathrm{Mg}^{2+}, \mathrm{NO}_{3}{ }^{-}$and $\mathrm{SO}_{4}{ }^{2-}$ ions.

In their study, $\mathrm{Li}$ and Wang [54] have illustrated that $\mathrm{K}^{+}, \mathrm{Na}^{+}, \mathrm{Ca}^{2+}, \mathrm{Mg}^{2+}$, sucrose and glucose do not interfere significantly, while L-glutamic acid, $\mathrm{Cu}^{2+}$ and $\mathrm{Fe}^{2+}$ ions showed a certain effect on the examinations of EP and UA.

Sadeghi et al. [75] studied the influence of various substances as potential interfering compounds on the determination of EP by the SWV method under optimum conditions. A study was performed by a novel biosensor based on ZnO nanoparticle/1,3-dipropylimidazolium bromide ionic liquid modified CPE. The tolerance limit was defined as the maximum concentration of the interfering substance like glucose, fructose, lactose, sucrose tryptophan, histidine, glycine, valine, methionine, lucine, alanine, phenylalanine, $\mathrm{Ca}^{2+}, \mathrm{Li}^{+}, \mathrm{ClO}_{4}{ }^{-}, \mathrm{SO}_{4}{ }^{2-}, \mathrm{SCN}^{-}, \mathrm{Na}^{+}, \mathrm{Mg}^{2+}, \mathrm{K}^{+}, \mathrm{AA}$, urea, cysteine and UA that caused an error less than $5 \%$ for the determination of EP. The results showed that the peak current of EP was not affected by all conventional cations, anions and organic substances.

As stated by Babaei et al. [70], interferences of AA, L-glutamic, L-alanin, aspartic acid and aspirin in determination of EP were significant only at relatively high concentrations, confirming that the proposed nickel hydroxide nanoparticles/MWCNTs modified GCE (MWCNT-NHNPs/GCE) was likely to be free from interferences from common components of biological samples.

Wang et al. [68] have illustrated the influence of some metal ions and anions that usually exist in biological fluid on the determination of $5.0 \times 10^{-5} \mathrm{~mol} / \mathrm{L}$ EP. If the $\pm 5 \%$ error was allowed, $5.0 \times 10^{-3} \mathrm{~mol} / \mathrm{L}$ of $\mathrm{K}^{+}, \mathrm{Na}^{+}, \mathrm{Fe}^{2+}, \mathrm{Mg}^{2+}, \mathrm{Cl}^{-}, \mathrm{SO}_{4}{ }^{2-}$ did not show obvious interference on a modified GCE, fabricated by covering with a layer of MWCNTs coated with hexadecyl trimethyl ammonium bromide (CTAB).

In another work, Apetrei et al. [63] investigated the influence of various interfering agents on determination of EP. The interfering substances $\mathrm{Na}^{+}, \mathrm{S}_{2} \mathrm{O}_{5}{ }^{2-}, \mathrm{Cl}^{-}$, urea, tartaric acid, hydrochloric acid, glucose and glycine did not show any influence on the biosensor response when detecting EP. An absence of significant modification of the peak current recorded in the presence of interfering species was demonstrated. Therefore, tyrosinase immobilized on a single-walled carbon nanotube modified GCE (tyrosinase/SWCNT-GCE) can be considered to be a good biosensor for recognition of EP.

Mazloum Ardakani et al. [66] studied the electrochemical behavior of a MWCNT paste electrode modified with 2-((7-(2,5-dihydrobenzylideneamino) heptylimino) methyl) benzene-1, 4-diol (DBHB). Influence of various foreign species like AA, DA, UA, levodopa, $\mathrm{N}$-acetyl and captopril at concentrations 5 times higher than EP did not show any interference in the determination of EP.

The influence of various foreign species on the determination of $50 \mu \mathrm{M}$ EP was investigated by Mekassa et al. [60] under optimum experimental conditions. Potentially interfering substances were chosen from the group of substances commonly found with EP in pharmaceutical formulations and biological fluids. The tolerance limit was defined as the maximum concentration of the foreign substance(s) that caused an approximately $\pm 5 \%$ relative error in the determination of EP. According to the obtained results, $\mathrm{AA}$, citric acid, D-glucose, lactose, glycine, $\mathrm{Mg}^{2+}, \mathrm{Ca}^{2+}, \mathrm{Na}^{+}$, and $\mathrm{K}^{+}$did not show any interference effect in the determination of EP.

Study of Vieira da Silva [61] showed that influence of interference on the electrode response can be useful to set up the sample preparation with the goal to minimize their effects. Interference from electroactive compounds typically present in a physiological sample (e.g., serotonin (SER), AA and 
UA) commonly hinders the accurate determination of EP. The selectivity of the sensor was examined in the presence of SER, AA and UA.

\section{Analytical performances of electrochemical epinephrine sensors}

The analytical performances of electrochemical methods depend on the sensor's construction and some of the most illustrative examples are extensively reviewed in Table 1.

Table 1. Some analytical performances attained in electrochemical determination of EP.

\begin{tabular}{|c|c|c|c|c|c|}
\hline $\begin{array}{l}\text { Type of } \\
\text { detection }\end{array}$ & Transducer & Linear response & $\begin{array}{l}\text { Detection } \\
\text { limit }\end{array}$ & $\begin{array}{l}\text { Relative } \\
\text { stand. dev. }\end{array}$ & Ref. \\
\hline $\begin{array}{l}\text { Voltammetry } \\
\text { (CV, DPV) }\end{array}$ & $\begin{array}{l}\text { L-glutamic acid functionalized graphene } \\
\text { nanocomposite, modified glassy carbon } \\
\text { electrode }\end{array}$ & $\begin{array}{l}10^{-7}-10^{-3} \\
\mathrm{~mol} \mathrm{~L}^{-1}\end{array}$ & $\begin{array}{l}3 \times 10^{-8} \\
\mathrm{~mol} \mathrm{~L}^{-1}\end{array}$ & $\leq 3.4 \%$ & [46] \\
\hline $\begin{array}{l}\text { Voltammetry } \\
\text { (DPV) }\end{array}$ & $\begin{array}{l}\beta \text {-Mercaptoethanol self-assembled } \\
\text { monolayer modified gold electrode }\end{array}$ & $\begin{array}{c}10^{-7}-10^{-4} \\
\mathrm{~mol} \mathrm{~L}^{-1}\end{array}$ & $\begin{array}{l}3.3 \times 10^{-8} \\
\mathrm{~mol} \mathrm{~L}^{-1}\end{array}$ & & [47] \\
\hline $\begin{array}{l}\text { Voltammetry } \\
\text { (CV, DPV) }\end{array}$ & $\begin{array}{l}\text { Glassy carbon electrode modified with } \\
\text { thiourea }\end{array}$ & $\begin{array}{c}5.0 \times 10^{-8}-1.1 \times 10^{-5} \\
\mathrm{~mol} \mathrm{~L}^{-1}\end{array}$ & $\begin{array}{l}2.3 \times 10^{-8} \\
\mathrm{~mol} \mathrm{~L}^{-1}\end{array}$ & $1.2 \%$ & [48] \\
\hline $\begin{array}{l}\text { Voltammetry } \\
\text { (CV, DPV) }\end{array}$ & $\begin{array}{l}\text { Tetradecyltrimethyl ammonium bromide } \\
\text { (TTAB) surfactant immobilized carbon } \\
\text { paste electrode }\end{array}$ & $\begin{array}{l}0.15-30 \\
\mu \mathrm{mol} \mathrm{L}\end{array}$ & $\begin{array}{c}0.12 \\
\mu \mathrm{mol} \mathrm{L}\end{array}$ & $2.4 \%$ & [49] \\
\hline $\begin{array}{l}\text { Voltammetry } \\
\text { (CV, DPV) }\end{array}$ & $\begin{array}{l}\text { Mesoporous carbon foam modified } \\
\text { glassy carbon electrode }\end{array}$ & $\begin{array}{l}0.1-12.0 \\
\mu \mathrm{mol} \mathrm{L}\end{array}$ & $40 \mathrm{nmol} \mathrm{L}^{-1}$ & & [50] \\
\hline $\begin{array}{l}\text { Voltammetry } \\
\text { (CV, DPV) }\end{array}$ & $\begin{array}{l}\text { Au-nanoparticle poly-fuchsine acid film } \\
\text { modified glassy carbon electrode } \\
\text { (poly(FA)/AuNP/GCE) }\end{array}$ & $\begin{array}{l}0.5-792.7 \\
\mu \mathrm{mol} \mathrm{L}\end{array}$ & $\begin{array}{c}0.01 \\
\mu \mathrm{mol} \mathrm{L} \mathrm{L}^{-1}\end{array}$ & $0.37 \%$ & [53] \\
\hline $\begin{array}{l}\text { Voltammetry } \\
(\mathrm{CV}, \mathrm{SWV})\end{array}$ & $\begin{array}{l}\text { Poly (guanine) modified glassy carbon } \\
\text { electrode (PGA/GCE) }\end{array}$ & $\begin{array}{c}10^{-5}-10^{-3} \\
\mathrm{~mol} \mathrm{~L}^{-1}\end{array}$ & $\begin{array}{l}1.8 \times 10^{-6} \\
\mathrm{~mol} \mathrm{~L}^{-1}\end{array}$ & & [54] \\
\hline $\begin{array}{l}\text { Voltammetry } \\
\text { (CV) }\end{array}$ & $\begin{array}{l}\text { Single-walled carbon nanotube-modified } \\
\text { glassy carbon electrode }\end{array}$ & $\begin{array}{c}10-110 \\
\mu \mathrm{mol} \mathrm{L}\end{array}$ & $\begin{array}{c}2.54 \\
\mu \mathrm{mol} \mathrm{L} \\
\end{array}$ & $3.4 \%$ & [63] \\
\hline $\begin{array}{l}\text { Voltammetry } \\
\text { (SWV) }\end{array}$ & $\begin{array}{l}\text { ZnO nanoparticle/1,3-dipropylimidazo- } \\
\text { lium bromide ionic liquid-modified } \\
\text { carbon paste electrode }\end{array}$ & $\begin{array}{l}0.09-800 \\
\mu \mathrm{mol} \mathrm{L}\end{array}$ & $\begin{array}{c}0.06 \\
\mu \mathrm{mol} \mathrm{L}\end{array}$ & $3.2 \%$ & [75] \\
\hline $\begin{array}{l}\text { Voltammetry } \\
\text { (CV, DPV) }\end{array}$ & $\begin{array}{l}\text { Glassy carbon electrode coated with a } \\
\text { novel Mg-Al layered double hydroxide- } \\
\text { nickel hydroxide nanoparticles-multi- } \\
\text { walled carbon nanotubes composite }\end{array}$ & $\begin{array}{l}0.04-60 \\
\mu \mathrm{mol} \mathrm{L}\end{array}$ & $\begin{array}{c}11.0 \\
\mathrm{nmol} \mathrm{L}\end{array}$ & $\leq 3.1 \%$ & [76] \\
\hline $\begin{array}{l}\text { Voltammetry } \\
\text { (CV) }\end{array}$ & $\begin{array}{l}\text { Gold nanoparticles/polyaniline } \\
\text { Langmuir-modified glassy } \\
\text { carbonelectrode }\end{array}$ & $\begin{array}{c}4 \times 10^{-7}-10^{-5} \\
\mathrm{~mol} \mathrm{~L}^{-1}\end{array}$ & $\begin{array}{l}8 \times 10^{-8} \\
\mathrm{~mol} \mathrm{~L}^{-1}\end{array}$ & $1.97 \%$ & [77] \\
\hline $\begin{array}{l}\text { Voltammetry } \\
\text { (DPAS) }\end{array}$ & $\begin{array}{l}\mathrm{MCM} / \mathrm{ZrO}_{2} \text { nanoparticles modified } \\
\text { carbon paste electrode }\end{array}$ & $\begin{array}{l}10^{-6}-2.5 \times 10^{-3} \\
\mathrm{~mol} \mathrm{~L}^{-1}\end{array}$ & $\begin{array}{l}5.0 \times 10^{-7} \\
\mathrm{~mol} \mathrm{~L}^{-1}\end{array}$ & & [79] \\
\hline $\begin{array}{l}\text { Voltammetry } \\
\text { (CV) }\end{array}$ & $\begin{array}{l}\text { A graphene-modified glassy carbon } \\
\text { electrode }\end{array}$ & $\begin{array}{l}0.20-100 \\
\mu \mathrm{mol} \mathrm{L}\end{array}$ & $\begin{array}{c}0.001 \\
\mu \mathrm{mol} \mathrm{L}\end{array}$ & & [83] \\
\hline $\begin{array}{l}\text { Voltammetry } \\
\text { (CV, DPV) }\end{array}$ & $\begin{array}{l}\text { Aminatedgraphene and Ag nanoparticles } \\
\text { modified GCE }\end{array}$ & $\begin{array}{c}0.916-184 \\
\mu \mathrm{mol} / \mathrm{L}\end{array}$ & $\begin{array}{c}2.0 \\
\mathrm{nmol} \mathrm{L}\end{array}$ & & [84] \\
\hline $\begin{array}{l}\text { Voltammetry } \\
(\mathrm{CV}, \mathrm{SWV})\end{array}$ & $\begin{array}{l}\text { Vinylferrocene and carbon nanotubes } \\
\text { (CNTs)-modified carbon paste electrode }\end{array}$ & $\begin{array}{c}0.1-1000.0 \\
\mu \mathrm{mol} \mathrm{L}\end{array}$ & $\begin{array}{l}3.0 \times 10^{-8} \\
\mathrm{~mol} \mathrm{~L}^{-1}\end{array}$ & $\leq 2.5 \%$ & [86] \\
\hline
\end{tabular}

\section{Some applications of electrochemical epinephrine sensors in pharmaceutical and biological fluid analysis}

Electrochemical EP sensors have widespread application in pharmaceutical and biomedical analysis, as shown in Table 2. 
Table 2. Numerical data on EP content determined in various analysed systems.

\begin{tabular}{|c|c|c|c|c|}
\hline Method & Electrode type & Analysed medium & Recovery, \% & Reference \\
\hline CV, DPV & $\begin{array}{l}\text { L-glutamic acid functionalized graphenenano- } \\
\text { composite, modified glassy carbon electrode }\end{array}$ & EP Injection & 100.4 & {$[46]$} \\
\hline DPAS & $\begin{array}{l}\beta \text {-Mercaptoethanol self-assembled monolayer } \\
\text { modified gold electrode }\end{array}$ & EP Injection & 100.9 & {$[47]$} \\
\hline $\mathrm{CV}$ & Glassy carbon electrode modified with thiourea & EP Injection & 101.2 & {$[48]$} \\
\hline DPV & $\begin{array}{l}\text { Tetradecyltrimethyl ammonium bromide } \\
\text { (TTAB) surfactant immobilized carbon paste } \\
\text { electrode }\end{array}$ & EP Injection & 96.3 & [49] \\
\hline DPV & $\begin{array}{l}\text { Glassy carbon, electrode coated with a novel } \\
\text { Mg-Al layered, double hydroxide-nickel } \\
\text { hydroxide nanoparticles, multi-walled carbon } \\
\text { nanotubes composite }\end{array}$ & $\begin{array}{l}\text { Blood } \\
\text { Urine }\end{array}$ & $\begin{array}{l}97.6 \\
98.2\end{array}$ & {$[76]$} \\
\hline DPV & $\begin{array}{l}\text { Gold nanoparticles/polyanilineLangmuir- } \\
\text { modified glassy carbonelectrode }\end{array}$ & Serum & 98.36 & [77] \\
\hline DPV & $\begin{array}{l}\mathrm{MCM} / \mathrm{ZrO}_{2} \text { nanoparticles modified, carbon } \\
\text { paste electrode }\end{array}$ & EP Injection & 101.7 & {$[79]$} \\
\hline DPV & Graphene-modified glassy carbon electrode & Urine & 99.7 & [83] \\
\hline DPV & $\begin{array}{l}\text { GCE, modified by aminatedgraphene and Ag } \\
\text { nanoparticles }\end{array}$ & Serum & 100.24 & [84] \\
\hline DPV & $\begin{array}{l}\text { Vinylferrocene and carbon nanotubes (CNTs)- } \\
\text { Modified Carbon Paste Electrode }\end{array}$ & $\begin{array}{l}\text { EP Injection } \\
\text { Ampoule }\end{array}$ & $\begin{array}{l}101.0 \\
102.0\end{array}$ & [86] \\
\hline
\end{tabular}

\section{Conclusions}

In past five years, utilization of electroanalytical methods for pharmaceutical analysis has significantly increased, especially for EP assessments. However, there is a limited number of publications concerning a combination of pre-concentration and electrochemical detection of EP. Electrochemical techniques are often preferred to laborious instrumental methods for EP determination, which is due to the simplicity of procedure and instrumentation, minimum requirements with respect to sample pretreatment, as well as fast response, sensitivity and low cost. Also, accurate results can be obtained in real time and complex media. Different modalities of sensor development already described in the literature are presented, starting from bare to chemically modified sensors. Recent advances imply the use of carbon nanotubes and various composites, for which large surface area and electrocatalytic activity greatly enhance the analytical signal, diminishes the peak potential corresponding to EP oxidation and solves peak overlapping problems in complex samples. Provided that adequate pretreatment and cleaning steps are included, several examples of viable EP determination in various media performed by bare electrodes, even in the presence of interfering compounds are also presented. Method performances and application areas depend on the chosen electrochemical technique. It can be generally concluded that different ways of construction and expected performances of sensor electrodes are adequate and tuned to the nature of the analysed compound and respective matrix. The nature of the electrode material and surface groups formed, as well as their interaction with analyte molecules, greatly influence the electrooxidation rate, as well as $\mathrm{pH}$ value of the analysed matrix, electrolyte type, and the peak potential and height. The mechanism and rate of electrooxidation are strongly dependent on the following factors: electrode nature and modifiers, electrode pre-treatment, surface groups, $\mathrm{pH}$, electrolyte and presence of other compounds. The interaction between the respective form of analyte molecule present at some $\mathrm{pH}$ value (range) and the functional groups of the electrode/modifier layer is found essential for determining electrooxidation rate and electrode 
performance. In complex media where interference is expected, modifiers enhance the catalytic peak current of the analyte of interest, allowing better peak separation from interfering compounds.

\begin{tabular}{|c|c|}
\hline \multicolumn{2}{|c|}{ Abbreviation } \\
\hline AA & Ascorbic acid \\
\hline CFE & Carbon film electrode \\
\hline CPE & Carbon paste electrodes \\
\hline CV & Cyclic voltammetry \\
\hline DA & Dopamine \\
\hline DPV & Differential pulse voltammetry \\
\hline EP & Epinephrine \\
\hline GCE & Glassy carbon electrode \\
\hline MWCNT & Multi walled carbon nanotube \\
\hline $\mathrm{NE}$ & Norepinephrine \\
\hline SWV & Square wave voltammetry \\
\hline SWNT & Single-walled carbon nanotube \\
\hline UA & Uric acid \\
\hline VAM & Vanilmandelic acid \\
\hline
\end{tabular}

\section{References}

[1] W. Ge Yun, Chinese Journal of Chemistry 23 (2005) 297-302.

[2] M. Mazloum Ardakani, H. Beitollahi, M. A. Sheikh Mohseni, A. Benvidi, H. Naeimi, M. Nejati-Barzoki, N. Taghavinia, Colloids and Surfaces B: Biointerfaces 76 (2010) 82-87.

[3] F. Ni, Y.Wang, D. Zhang, M. Li, Electroanalysis 22 (2010) 1130-1135.

[4] J. X. Qiao, H. Q. Luo, N. B. Li, Colloids and Surfaces B: Biointerfaces 62 (2008) 31-35.

[5] W. Ren, H. Q. Luo, N. B. Li, Sensors 6 (2006) 80-89.

[6] T. Łuczak, Electroanalysis 21 (2009) 2557-2562.

[7] X. H Zhang, Sh. F. Wang, Analytical Letters 35 (2002) 995-1006.

[8] A. A. Ensafi, M. Taei, T. Khayamian, Colloids and Surfaces B: Biointerfaces 79 (2010) 480-487.

[9] M. Taei, M. Jamshidi, Journal of Solid State Electrochemistry 18 (2014) 673-683.

[10] S. Y. Ly, Analytical Letters 45 (2012) 1197-1203.

[11] M. Taei, H. Hadadzadeh, F. Hasanpour, N. Tavakkoli, M. Hadadi Dolatabadi, lonics 21 (2015) 3267-3278.

[12] N. B. Li, L. M. Niu, H. Q. Luo, Microchimica Acta 153 (2006) 37-44.

[13] M. Mazloum-Ardakani, H. Beitollahi, M. K. Amini, B. F. Mirjalili, F. Mirkhalaf, Journal of Electroanalytical chemistry 651 (2011) 243-249.

[14] Y. X. Sun, S. Fu Wang, X. H. Zhang, Y. F. Huang, Sensors and Actuators B: Chemical 113 (2006) 156-161.

[15] H. Beitollahi, H. Karimi-Maleh, H. Khabazzadeh, Analytical Chemistry 80 (2008) 9848-9851.

[16] H. Beitollahi, M. Mazloum Ardakani, B. Ganjipour, H. Naeimi, Biosensors and Bioelectronics 24 (2008) 362-368.

[17] T. Tavana, M. A. Khalilzadeh, H. Karimi-Maleh, A. A. Ensafi, H. Beitollahi, D. Zareyee, Journal of Molecular Liquids 168 (2012) 69-74.

[18] H. Beitollahi, I. Sheikhshoaie, Analytical Methods 3 (2011) 1810-1814.

[19] M. Mazloum-Ardakani, H. Beitollahi, M. K. Amini, F. Mirkhalaf, M. Abdollahi-Alibeik, Analytical Methods 3 (2011) 673-677.

[20] H. Mahmoudi Moghaddam, H. Beitollahi, S. Tajik, H. Soltani, Electroanalysis 27 (2015) 2620-2628.

[21] F. Wang, Y. Xu, L. Wang, K. Lu, B. Ye, Journal of Solid State Electrochemistry 16 (2012) 2127-2133.

[22] W. Ma, D. M. Sun, Chinese Journal of Analytical Chemistry 35 (2007): 66-70.

[23] S. Shahrokhian, R. S. Saberi, Electrochimica Acta 57 (2011) 132-138.

[24] F. Cui, X. Zhang, Journal of Electroanalytical Chemistry 669 (2012) 35-41.

[25] M. A. Fotopoulou, P. C. Ioannou, Analytica Chimica Acta 462 (2002) 179-185. 
[26] S. Shelkovnikov, H. C. Gonick, Life sciences 75 (2004) 2765-2773.

[27] V. Carrera, E. Sabater, E. Vilanova, M. A. Sogorb, Journal of Chromatography B 847 (2007) 88-94.

[28] X. Zhu, P. N. Shaw, D. A. Barrett, Analytica Chimica Acta 478 (2003) 259.

[29] F. DP. Ferreira, L. IB Silva, A. C. Freitas, T. AP Rocha-Santos, A. C. Duarte, Journal of Chromatography A 1216 (2009) 7049-7054.

[30] L. IB Silva, F. DP. Ferreira, A. C. Freitas, T. AP. Rocha-Santos, A. C. Duarte, Talanta 80 (2009) 853-857.

[31] L. Zhang, S. Qv, Z. Wang, J. Cheng, Journal of Chromatography B 792 (2003) 381-385.

[32] Sh. Wei, G. Song, J .M. Lin, Journal of Chromatography A 1098 (2005) 166-171.

[33] E. M. Garrido, J. LFC. Lima, C. Delerue-Matos, Journal of Pharmaceutical and Biomedical Analysis 15 (1997) 845-849.

[34] J. J. Willemsen, H. A. Ross, M. C. Jacobs, J. W. Lenders, T. H. Thien, L. M. Swinkels, T. J. Benraad, Clinical Chemistry 41 (1995) 1455-1460.

[35] Y. Su, J. Wang, G. Chen, Talanta 65 (2005) 531-536.

[36] J. Michałowski, P. Hałaburda, Talanta 55 (2001) 1165-1171.

[37] M. H. Sorouraddin, J. L. Manzoori, E. Kargarzadeh, A. M. Haji Shabani, Journal of Pharmaceutical and Biomedical Analysis 18 (1998) 877-881.

[38] M. Zhu, X. Huang, J. Li, H. Shen, Analytica Chimica Acta 357 (1997) 261-267.

[39] X. Ma, M. Chao, Z. Wang. Analytical Methods 4 (2012) 1687-1692.

[40] X. Ma, M. Chen, X. Li, A. Purushothaman, F. Li, International Journal of Electrochemical Science 7 (2012) 991-1000.

[41] Y. Zhang, W. Ren, Sh. Zhang, International Journal of Electrochemical Science 8 (2013) 6839-6844.

[42] H. Beitollahi, S. Nekooei, M. Torkzadeh-Mahani, Talanta 188 (2018) 701-707.

[43] H. Beitollahi, S. Ghofrani Ivari, M. Torkzadeh-Mahani, Biosensors and Bioelectronics 110 (2018) 97-102.

[44] J. Li, E. Shangguan, D. Guo, F. Gao, Q. Li, X. Z. Yuan, H. Wang, Electrochimica Acta 186 (2015) 209-215.

[45] Z. Jemelkova, J. Barek, J. Zima, Analytical Letters 43 (2010) 1367-1376.

[46] H. Kang, Y. Jin, Q. Han, Analytical Letters 47 (2014) 1552-1563.

[47] Z. Xiu-Hua, Sh. F. Wang, Analytical Letters 35 (2013) 995-1006.

[48] M. A. Yazdely, M. A. Taher, S. Tajik, Analytical \& Bioanalytical Electrochemistry 5 (2013) 517-522.

[49] S. Shankar, B. E. Kumara Swamy, International Journal of Electrochemical Science 9 (2014) 1321-1339.

[50] M. Jahanbakhshi, Materials Science and Engineering C 70 (2017) 544-551.

[51] B. N. Chendrashekar, B. E. Kumara Swamy, K. J. Gururaj, C. Cheng, Journal of Molecular Liquids 231 (2017) 379-385.

[52] M. D. Tezerjani, A. Benvidi, A. Dehghani Firouzabadi, M. Mazloum-Ardakani, A. Akbari, Measurement 101 (2017) 183-189.

[53] M. Taei, F. Hasanpour, N. Tavakkoli, M. Bahrameian, Journal of Molecular Liquids 211 (2015) 353-362.

[54] Li. I. Hongying, W. A. N. G. Xueliang, Electrochemistry 83 (2015) 434-439.

[55] Ç. Koçak, Z. Dursun, Journal of Electroanalytical Chemistry 694 (2013) 94-103.

[56] B. Devadas, M. Rajkumar, Sh. M. Chen, Colloids and Surfaces B: Biointerfaces 116 (2014) 674-680.

[57] M. Taei, M. Jamshidi, Journal of Solid State Electrochemistry 18 (2014) 673-683.

[58] W. Ma, X. Yao, D. Sun, Asian Journal of Chemistry 25 (2013) 6625-6632.

[59] H. Li, D. Sun, Asian Journal of Chemistry 27 (2015) 2539-2542.

[60] B. Mekassa, M. Tessema, B. S. Chandravanshi, P. GL Baker, F. N. Muya. Journal of Electroanalytical Chemistry 807 (2017) 145-153.

[61] S. da, L. Vieira, C. Bezerra Lopes, W. Ceciliano d. Silva, Y. Galdino d. Paiva, F. de Assis dos Santos Silva, P. Rodrigues Lima, L. Tatsuo Kubota, M. Oliveira Fonseca Goulart. Microchemical Journal 133 (2017) 460-467.

[62] H. Mao, H. Zhang, W. Jiang, J. Liang, Y. Sun, Y. Zhang, Q. Wu, G. Zhang, X. M. Song. Materials Science and Engineering: C 75 (2017) 495-502.

[63] I. M. Apetrei, C. Apetrei, International Journal of Nanomedicine 8 (2013) 4391-4399.

[64] F. Valentini, E. Ciambella, V. Conte, L. Sabatini, N. Ditaranto, F. Cataldo, G. Palleschi, Biosensors and Bioelectronics 59 (2014) 94-106.

[65] M. E. Ghica, Ch. M. A. Brett, Analytical Letters 46 (2013) 1379-1393.

[66] M. Mazloum-Ardakani, F. Sabbaghian, B. F. Mirjalili, M. A. Sheikh-Mohseni, Analytical and Bioanalytical Electrochemistry 6 (2014) 106-119. 
[67] Y. Wu, X. Feng, Sh. Zhou, H. Shi, H. Wu, Sh. Zhao, W. Song, Microchimica Acta 180 (2013) 1325-1332.

[68] X. Wang, J. Li, Z. Yu, International Journal of Electrochemical Science 10 (2015) 93-101.

[69] H. Rajabi, M. Noroozifar, M. Khorasani-Motlagh, Analytical \& Bioanalytical Electrochemistry 8 (2016) 522-531.

[70] A. Babaei, E. Rezaei, M. Sohrabi, O. Karbalaei Hasani, Analytical \& Bioanalytical Electrochemistry 7 (2015) 302-311.

[71] P. Pradhan, R. J. Mascarenhas, T. Thomas, I. N. N. Namboothiri, O. J. D'Souza, Z. Mekhalif, Journal of Electroanalytical Chemistry 732 (2014) 30-37.

[72] T. Thomas, R. J. Mascarenhas, O. J. D'Souza, S. Detriche, Z. Mekhalif, P. Martis, Talanta 125 (2014) 352360.

[73] F. Figueiredo, L.CS. Tiago, A. Silva, F. C. Vicentini, O. Fatibello-Filho, Analyst 139 (2014) 2842-2849.

[74] K. K Reddy, M. Satyanarayana, K. Yugender Goud, K. Vengatajalabathy Gobi, Materials Science and Engineering C 79 (2017) 93-99.

[75] R. Sadeghi, H. Karimi-Maleh, A. Bahari, M. Taghavi. Physics and Chemistry of Liquids 51 (2013) 704-714.

[76] A. Babaei, M. Afrasiabi, Gh. Azimi, Analytical Methods 7 (2015) 2469-2478.

[77] L. Zou, Y. Li, Sh. Cao, B. Ye, Talanta 117 (2013) 333-337.

[78] I. E. Silai, I. C. Fort, D. Casoni, G. L. Turdean, Revue Roumane de Chimie 60 (2015) 689-696.

[79] M. Mazloum-Ardakani, A. Dehghani-Firouzabadi, N. Rajabzade, M. A. Sheikh-Mohseni, A. Benvidi, M. Abdollahi-Alibeik, Journal of the Iranian Chemical Society 10 (2013) 1-5.

[80] B. Jin, H. Zhang. Analytical Letters 35 (2014) 1907-1918.

[81] A. S.Razaviansra, S. M. Ghoreishi, A. S. Esmaeily, M. Behpour, L. MA Monzon, J. M. D. Coey, Microchimica Acta 181 (2014) 1947-1955.

[82] Q. Yang, Y. Zhao, J. Bai, L. Wu, H.M. Zhang, L. Qu, Analytical Methods 7 (2015) 10394-10402.

[83] M. F. Chen, X. Y. Ma, Russian Journal of Applied Chemistry 87 (2014) 200-206.

[84] H. Xu, X. Wang, R. Chen, Z. Yu, Chemical Research in Chinese Universities 30 (2014) 205-210.

[85] Ch. H. Mak, C. Liao, Y. Fu, M. Zhang, Ch. Y. Tang, Y. H. Tsang, H. LW Chan, F. Yan, Journal of Materials Chemistry C 3 (2015) 6532-6538.

[86] H. Beitollahi, M. A. Taher, A. Hosseini, Measurement 51 (2014) 156-163.

[87] Kang, Hongzhe, Yan Jin, Qian Han, Analytical Letters 47 (2014) 1552-1563.

[88] G. Ibáñez-Redín, D. Wilson, D. Gonçalves, O. N. Oliveira, Journal of Colloid and Interface Science (2017). https://doi.org/10.1016/j.jcis.2017.12.085

[89] V. K. Gupta, H. Mahmoody, F. Karimi, Sh. Agarwal, M. Abbasghorbani. International Journal of Electrochemical Science 12 (2017) 248-257.

[90] A. C. Anithaa, K. Asokan, C. Sekar. Electrochimica Acta 237 (2017) 44-53.

[91] T. P Tsele, A. S. Adekunle, E. F. Omolola, E. E. Eno, Electrochimica Acta 243 (2017) 331-348.

(C2019 by the authors; licensee IAPC, Zagreb, Croatia. This article is an open-access article distributed under the terms and conditions of the Creative Commons Attribution license

(http://creativecommons.org/licenses/by/4.0/) 